\title{
Aerobic Bacteriological Profile and Antibiogram of Surgical Site Infections in a Tertiary Care Hospital in Kashmir
}

\author{
Afreen Rashid, Talat Masoodi, Amrish Kohli*, Sumaira Qayoom, \\ Syed Arshi and Syed Khursheed
}

Department of Microbiology, SKIMS Medical College, Bemina, Srinagar-190017, J\&K, India

*Corresponding author

\begin{tabular}{|l|}
\hline Ke y w o r d s \\
Surgical site \\
infections, \\
$\begin{array}{l}\text { Escherichia coli, } \\
\text { Staphylococcus } \\
\text { aureus, CONS }\end{array}$ \\
\hline Article Info \\
\hline $\begin{array}{l}\text { Accepted: } \\
15 \text { March } 2019 \\
\text { Available Online: } \\
10 \text { April } 2019\end{array}$ \\
\hline
\end{tabular}

A B S T R A C T

To determine the most common organisms causing surgical site infections and their antibiotic sensitivity pattern. This study was carried out retrospectively in the Department of Microbiology SKIMS Medical College and associated hospital, Srinagar for a period of two years (January 2017-December 2018). A total number of 194 pus samples of inpatients from different wards as well as of out-patients were processed using standard microbiological techniques. Of the 194 pus samples processed, 94 samples were culture positive (48.4\%). Escherichia coli was the most commonly isolated organism (36\%) followed by Staphylococcus spp. (34\%), Klebsiella spp. (11.7\%), Acinetobacter spp. (5.3\%), Enterococcus spp. (4.25\%), Coagulase negative Staphylococci (CONS) (3.1\%), Citrobacter spp. (2.12\%), Pseudomonas spp. (2.1\%) and Proteus spp. (1.06\%). All isolates of Escherichia coli were sensitive to Polymyxin-B and 90\% sensitive to Imipenem. 14 E.coli isolates (41.17\%) were multi-drug resistant. 100\% of Staphylococcus and Enterococcus spp. were sensitive to Linezolid, Vancomycin and Teicoplanin. 15(46.87\%) isolates of Staphylococcus aureus were Methicillin-resistant Staphylococcus aureus. Surgical site infections are an important cause of morbidity, mortality and economic burden among health care associated infections (HCAI). Absence of data, under-reporting and little or no surveillance of these infections are major areas of concern.

\section{Introduction}

Surgical site infections (SSI's) or infections at the site of surgical incision wounds are defined as microbial infiltration of the wounds occurring upto 30 days after surgery, or upto one year after surgery in patients receiving implants, and affecting either the incision or deep tissue above fascial layer at operation site. ${ }^{[1]}$ These are the third most common cause of hospital-associatedinfections worldwide and remain as one of the most important post-operative complications accounting for $10-20 \%$ of hospital cost. ${ }^{[2]}$ Surgical procedures with complications have magnanimous impacts on health expenditures and increased duration of hospital stay. ${ }^{[3]}$ Sepsis in surgery thus consistently remains a significant concern to the health professionals worldwide. ${ }^{[4]}$

Indiscriminate and injudicious use of 
antibiotics has led to the progressive development of multidrug resistance that is an important cause of increased morbidity and mortality ${ }^{[5]}$

The multidrug resistant virulent organisms thriving in the hospitals are capable of causing disease in patients already compromised with injury, surgery, pregnancy, immune status and other co-morbid conditions over and above the use of broad spectrum antibiotics which reduce the normal microbial flora of the body ${ }^{[6,7]}$

The pathogens most frequently isolated from the pus samples of surgical sites are Staphylococcus aureus, Escherichia coli, Pseudomonas aeruginosa, and Klebsiella spp. ${ }^{[8]}$ All these bacteria are relevant in hospital environments that encounter intense selection pressure of extensive antibiotic therapy for a range of bacterial infections.

It is estimated that about half of the SSI's are preventable using evidence based strategies. The prevention of SSI's is increasingly important as the number of surgical procedures continue to rise. CDC has pointed out that the single most important measure for preventing the spread of nosocomial bacterial pathogens is effective hand washing. Handwash is recommended before and after contact with patients, before invasive procedures and after contact with contaminated inanimate objects ${ }^{[9]}$

In the present study, we aim to analyze cases of surgical site infections over a period of two years for the spectrum of pathogenic bacteria isolated and their antibiotic sensitivity pattern. This will be a step towards the development of institutional antimicrobial policies for empirical and culture guided therapies and also to formulate effective measures for control of hospital associated infections.

\section{Materials and Methods}

\section{Study period and site}

The present study was conducted in the Department of Microbiology Sher-i-Kashmir institute of Medical sciences Medical college and hospital, Bemina, Srinagar for a period of two years from Jan 2017 to Dec 2018.

\section{Study type}

Retrospective observational study

\section{Sample size}

194 samples collected from both out-patients as well as in-patients were processed.

\section{Inclusion criteria}

Samples from elective and emergency surgeries with

Signs of inflammation like tenderness, redness, sanguineous or purulent discharge or fever $\geq 38^{\circ} \mathrm{C}^{[10]}$

Gaping wound. ${ }^{[10]}$

\section{Exclusion criteria}

Skin grafts.

Patient lost on follow-up.

Incision and drainage.

\section{Methodology}

Samples taken on swab or frank pus in syringes were processed using standard microbiological techniques. Following sequence of steps were taken in sample processing:

All samples were subjected to direct gram staining technique for presumptive evidence. This was followed by inoculation on routine 
laboratory media like blood agar, MacConkey agar and chocolate agar. ${ }^{[11]}$

After aerobically incubating the media at $37^{\circ} \mathrm{C}$ for $24 \mathrm{hrs}$, any growth was studied for their colony characteristics including color, shape, size, texture or pattern of haemolysis if present.

Biochemical tests and spot tests were performed to confirm the organisms. ${ }^{[12]}$

Antimicrobial susceptibility testing of all isolates was performed using Kirby-Bauer's disc diffusion method following the CLSI guidelines. ${ }^{[13]}$

No growth obtained even after 48 hrs of incubation at $37^{\circ} \mathrm{C}$ was labeled as sterile pus and were included in the present study.

\section{Results and Discussion}

A total of 194 pus samples were included in the study. Among these 194 samples, 94 samples showed significant growth and the rest of samples with no growth were labeled as sterile. Thus the total number of culture positive cases was $48.45 \%$.

However, the percentage of culture positive cases were significantly more in emergency surgeries $(54.8 \%)$ as compared to elective surgeries $(39.50 \%)$. The results are depicted in Table 1.

The highest number of culture positive cases were observed from the department of orthopedics which mostly included trauma and road traffic accidents, followed by emergency surgeries like gut perforation, exploratory laparotomy following trauma, staging laparotomy etc.

A percentage wise distribution of culture positivity rates in various surgeries performed in our institute is given below in table 2 .
Not much difference was observed in the percentage of surgical site infections among the two genders. Among the 194 cases studied, 103 were males (53.09\%) and 91 were females $(46.90 \%)$. However most of the males had undergone emergency surgeries due to injuries in road traffic accidents while most of the females had undergone elective surgeries mostly for gaenecological and obstetric reasons followed by cholecystectomy (Figure 1).

Table 3 highlights the most common organisms isolated in our study. E coli $(36 \%)$ was observed to be the most frequent isolate followed by Staphylococcus aureus (34\%), Klebsiella spp. (11.7\%), Acinetobacter spp. (5.3\%), Enterococcus spp. (4.25\%), CONS (3.1\%), Pseudomonas spp. (2.1\%), Citrobacter spp. (2.12\%) and Proteus spp. $(1.06 \%)$. Most of these bacteria isolated are known causes of hospital acquired infections.

A total of 39 gram-positive organisms $(41.48 \%)$ were isolated and their antibiotic sensitivity pattern determined. All isolates of Staphylococcus aureus, Enterococcus spp. and Coagulase negative Staphylococci were found sensitive to Teicoplanin, Vancomycin and Linzolid. However a considerable number of isolates of Staphylococcus aureus were found resistant to $\beta$ lactams, aminoglycosides, and fluoroquinolones. The antibiotic sensitivity pattern of Gram positive bacterial isolates is given below in Table 4 .

Most of the isolates of Escherichia coli and Klebsiella spp., the two most frequently isolated Gram negative species in our study, were resistant to Amoxy-clav, Ceftriaxone, Cefepime, Ciprofloxacin, Ofloxacin and Cotrimoxazole. On the other hand, sensitivity to Piperacillin-Tazobactum, Amikacin, Tobramycin, Imipinem and Polymyxin B was considerably higher. The antimicrobial sensitivity of Gram negative isolates is given below in Table 5 . 
Table.1 Culture positivity rates from surgical site pus samples

\begin{tabular}{|c|c|c|c|}
\hline Type of surgery & No of pus samples processed & Culture positive cases & Percentage \\
\hline Emergency & 113 & 62 & $54.8 \%$ \\
\hline Elective & 81 & 32 & $39.50 \%$ \\
\hline Total & 194 & 94 & $48.45 \%$ \\
\hline
\end{tabular}

Table.2 Percentage of culture positive cases in various surgeries

\begin{tabular}{|l|c|c|c|}
\hline \multicolumn{1}{|c|}{ Type of surgery } & Cases processed & $\begin{array}{c}\text { Culture } \\
\text { positive }\end{array}$ & Percentage \\
\hline Implants (Orthopaedic) & 29 & 15 & $51.72 \%$ \\
\hline Non-implants (Orthopaedic) & 28 & 19 & $67.85 \%$ \\
\hline $\begin{array}{l}\text { Appendectomy } \\
\text { Cholecystectomy }\end{array}$ & 28 & 17 & $60.71 \%$ \\
\hline Hernioplasty gut & 31 & 10 & $32.25 \%$ \\
\hline $\begin{array}{l}\text { Others } \\
\text { perforation/laparotomy/ } \\
\text { breast surgeries/staging laparotomy. }\end{array}$ & 13 & 4 & $30.76 \%$ \\
\hline LSCS & 24 & 16 & $66.66 \%$ \\
\hline Non-LSCS & & & \\
\hline
\end{tabular}

Table.3 Aerobic bacterial culture isolates with culture positive rates

\begin{tabular}{|l|c|c|}
\hline Organisms isolated & No. of isolates & Percentage \\
\hline Escherichia coli & 34 & $36 \%$ \\
\hline Staphylococcus aureus & 32 & $34 \%$ \\
\hline Klebsiella spp. & 11 & $11.7 \%$ \\
\hline Acinetobacter spp. & 5 & $5.3 \%$ \\
\hline Enterococcus spp. & 4 & $4.25 \%$ \\
\hline Coagulase negative Staphylococcus & 3 & $3.1 \%$ \\
\hline Pseudomonas spp. & 2 & $2.1 \%$ \\
\hline Citrobacter spp. & 2 & $2.12 \%$ \\
\hline Proteus spp. & 1 & $1.06 \%$ \\
\hline
\end{tabular}


Table.4 Antibiotic sensitivity profile of gram-positive organisms isolated

\begin{tabular}{|l|l|c|c|c|}
\hline S.no. & Antimicrobials & Staphylococcus aureus $\mathbf{( n = 3 2 )}$ & Enterococcus spp. $(\mathbf{n = 4})$ & CONS (n=3) \\
\hline $\mathbf{1}$ & Penicillin & $11(34.37 \%)$ & 0 & 0 \\
\hline $\mathbf{2}$ & Ampicillin & $\mathrm{nt}$ & $1(25 \%)$ & 0 \\
\hline $\mathbf{3}$ & Cefoxitin & $15(46.87 \%)$ & $\mathrm{nt}$ & $2(66.66 \%)$ \\
\hline $\mathbf{4}$ & Cefazolin & $18(56.25 \%)$ & 0 & $2(66.66 \%)$ \\
\hline $\mathbf{5}$ & Amox-clav & $19(59.37 \%)$ & $3(75 \%)$ & 0 \\
\hline $\mathbf{6}$ & Cotrimoxazole & $24(75 \%)$ & $1(25 \%)$ & $3(100 \%)$ \\
\hline $\mathbf{7}$ & Amikacin & $25(78.12 \%)$ & $2(25 \%)$ & $2(66.66 \%)$ \\
\hline $\mathbf{8}$ & Gentamycin & $22(68.75 \%)$ & $\mathrm{nt}$ & $2(66.66 \%)$ \\
\hline $\mathbf{9}$ & Erythromycin & $21(65.62 \%)$ & $\mathrm{nt}$ & $1(33.33 \%)$ \\
\hline $\mathbf{1 0}$ & Azithromycin & $22(68.75 \%)$ & $4(100 \%)$ & $2(66.66 \%)$ \\
\hline $\mathbf{1 1}$ & Teicoplanin & $100(100 \%)$ & $2(50 \%)$ & $4(100 \%)$ \\
\hline $\mathbf{1 2}$ & Ciprofloxacin & $17(53.12 \%)$ & $\mathrm{nt}$ & $1(33.33 \%)$ \\
\hline $\mathbf{1 3}$ & Ofloxacin & $19(59.3 \%)$ & $3(75 \%)$ & $2(66.66 \%)$ \\
\hline $\mathbf{1 4}$ & Levofloxacin & $20(62.5 \%)$ & $\mathrm{nt}$ & $2(66.66 \%)$ \\
\hline $\mathbf{1 5}$ & Clindamycin & $26(81.25 \%)$ & $4(100 \%)$ & $2(66.66 \%)$ \\
\hline $\mathbf{1 6}$ & Vancomycin & $100(100 \%)$ & $4(100 \%)$ & $3(100 \%)$ \\
\hline $\mathbf{1 7}$ & Linezolid & $100(100 \%)$ & $3(100 \%)$ \\
\hline
\end{tabular}

$\mathrm{nt}=$ not tested, CONS=Coagulase negative Staphylococcus

Table.5 Antibiotic sensitivity profile of gram-negative organism

\begin{tabular}{|c|c|c|c|c|c|c|c|}
\hline S.no. & Antimicrobial & $\begin{array}{l}E \text { coli } \\
\mathrm{n}=34\end{array}$ & $\begin{array}{c}\text { Klebsiella } \\
\text { spp. } \\
\text { n=11 }\end{array}$ & $\begin{array}{c}\text { Acinetobacter } \\
\text { spp. } \\
n=5\end{array}$ & $\begin{array}{c}\text { Pseudomonas } \\
\text { spp. } \\
\mathrm{n}=2\end{array}$ & $\begin{array}{l}\text { Citrobacter } \\
\text { spp. } \quad n=2\end{array}$ & $\begin{array}{c}\text { Proteus spp. } \\
n=1\end{array}$ \\
\hline 1 & Ampicillin & & $0(0.00 \%)$ & $0(0.00 \%)$ & $0(0.00 \%)$ & $0(0.00 \%)$ & $0(0.00 \%)$ \\
\hline 2 & Amox-clav & $6(17.6 \%)$ & $0(0.00 \%)$ & $0(0.00 \%)$ & $0(0.00 \%)$ & $0(0.00 \%)$ & $0(0.00 \%)$ \\
\hline 3 & Ceftriaxone & $9(26.47 \%)$ & $3(27.27 \%)$ & $0(0.00 \%)$ & $\mathrm{nt}$ & $0(0.00 \%)$ & $1(100 \%)$ \\
\hline 4 & Cefepime & $11(32.35 \%)$ & $2(18.18 \%)$ & $0(0.00 \%)$ & $0(0.00 \%)$ & $1(50 \%)$ & \\
\hline 5 & Ceftazidime & $16(47.05 \%)$ & $2(18.18 \%)$ & $0(0.00 \%)$ & $1(50.00 \%)$ & $1(50 \%)$ & $1(100 \%)$ \\
\hline 6 & $\begin{array}{l}\text { Ceftazidime/ } \\
\text { clauvanic acid }\end{array}$ & $19(55.88 \%)$ & $4(36.36 \%)$ & $0(0.00 \%)$ & $2(100.00 \%)$ & $1(50 \%)$ & $1(100 \%)$ \\
\hline 7 & Cefprome & & & $0(0.00 \%)$ & $0(0.00 \%)$ & $1(50 \%)$ & $0(0.00 \%)$ \\
\hline 8 & $\begin{array}{l}\text { Pipercillin/ } \\
\text { tazobactam }\end{array}$ & $24(70.58 \%)$ & $7(63.6 \%)$ & $0(0.00 \%)$ & $2(100 \%)$ & $1(50 \%)$ & $1(100 \%)$ \\
\hline 9 & Gentamycin & $22(64.7 \%)$ & $4(36.36 \%)$ & $2(40 \%)$ & $1(50 \%)$ & $1(50 \%)$ & \\
\hline 10 & Amikacin & $30(88.2 \%)$ & $7(63.6 \%)$ & $4(80 \%)$ & $1(50 \%)$ & $1(50 \%)$ & $1(100 \%)$ \\
\hline 11 & Tobramycin & $20(58.8 \%)$ & $6(54.54 \%)$ & $2(40 \%)$ & $1(50 \%)$ & $1(50 \%)$ & $1(100 \%)$ \\
\hline 12 & Ciprofloxicin & $4(11.76 \%)$ & $3(27.27 \%)$ & $1(20 \%)$ & $1(50 \%)$ & $1(50 \%)$ & $1(100 \%)$ \\
\hline 13 & Ofloxacin & $10(29.41 \%)$ & $4(36.36 \%)$ & $2(40 \%)$ & $0(0.00 \%)$ & $1(50 \%)$ & $0(0.00 \%)$ \\
\hline 14 & Meropenem & $23(67.64 \%)$ & $3(36.36 \%)$ & $3(60 \%)$ & $1(50 \%)$ & $0(0.00 \%)$ & $0(0.00 \%)$ \\
\hline 15 & Imepenem & $31(91.1 \%)$ & $11(100 \%)$ & $3(60 \%)$ & $1(50 \%)$ & $1(50 \%)$ & $1(100 \%)$ \\
\hline 016 & Cotrimoxizole & $9(26.47 \%)$ & $6(54.54 \%)$ & $0(0.00 \%)$ & $\mathrm{nt}$ & $0(0.00 \%)$ & $0(0.00 \%)$ \\
\hline 17 & Polymixin B & $34(100 \%)$ & $11(100 \%)$ & $5(100 \%)$ & $2(100 \%)$ & $2(100 \%)$ & $0(0.00 \%)$ \\
\hline 18 & Tigecycline & nt & $\mathrm{nt}$ & $5(100 \%)$ & $\mathrm{nt}$ & $\mathrm{nt}$ & $0(0.00 \%)$ \\
\hline
\end{tabular}

$\mathrm{nt}=$ not tested, $\mathrm{n}=$ total number of isolates tested 
Fig.1 Gender distribution of culture positive cases

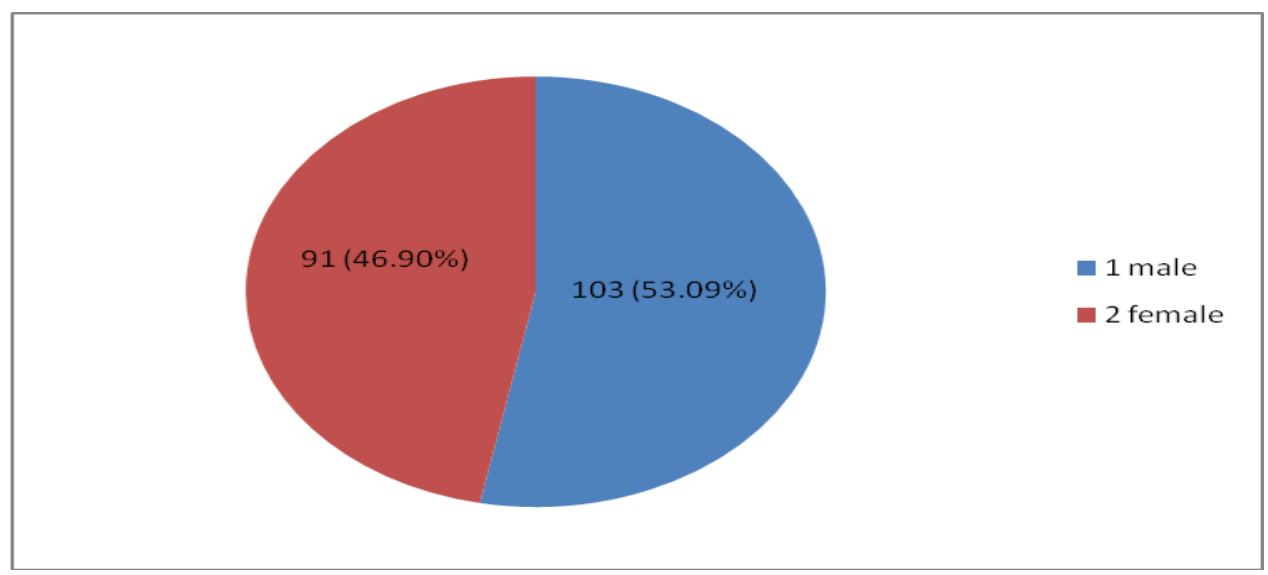

The infection rate is higher in patients who underwent emergency surgeries than those who underwent elective surgeries. This is in concordance with studies by Lilani SP et al and Anvikar AR et al. ${ }^{[10,14]}$

The highest number of culture positive cases were from orthopedic surgeries which mostly included trauma and RTA's, followed by emergency surgeries like gut perforation, exploration laparotomy following trauma, staging laparotomy etc.

Of the 194 samples processed, 94(48.45\%) showed bacterial growth after 24 hours of aerobic inoculation. The low percentage of culture positivity may be because of the reason that patients were already on empirical therapy that rendered pus samples sterile and secondly anaerobes were not tested because of unavailability of anaerobic culture. The percentage of culture positive cases were significantly more in emergency surgeries $(54.8 \%)$ as compared to elective surgeries $(39.5 \%)$ which is similar to some other studies. $^{[15,16,17]}$

E coli $(36 \%)$ was the most frequently isolated pathogen in this study. This was followed by Staphylococcus aureus (34\%), Klebseilla spp. (11.7\%), Acinetobacter spp. (5.3\%), Enterococcus spp. (4.25\%), CONS (3.1\%),
Pseudomonas spp. (2.1\%), Citrobacter spp. $(2.12 \%)$ and Proteus spp. (1.06\%). Similar spectrum of bacterial profile was observed in some other studies. ${ }^{[16,18,19]}$

Gram negative bacilli showed 100\% sensitivity to Polymixin-B, which is in concordance with most of the studies. E coli showed maximum sensitivity to Imipenem (91.1\%). Two multidrug resistant strains of $E$ coli were sensitive only to Polymixin-B. Klebseilla spp. was $100 \%$ sensitive to Imipenem and $100 \%$ resistance to amoxicillin-clavulanic acid. Acinetobacter spp. were $100 \%$ sensitive to Tigecycline followed by $80 \%$ sensitivity to Tobramycin. These drugs should however be used in selected cases and must be kept as reserve drugs for risk of acquired resistance against them.

Pseudomonas spp. were $100 \%$ sensitive to Pipercillin-Tazobactam and ceftazidimeclavulanic acid but $50 \%$ of isolates were found resistant to Carbapenems and Aminoglycosides. that was in concordance to some studies. ${ }^{[20,21]}$

All the gram-positive organisms were sensitive to Vanomycin (100\%), Linezolid $(100 \%)$ and Teicoplanin (100\%) which is in concordance to the study by V.Singh et al. ${ }^{[19]}$ 
A high susceptibility rate of Staphylococcus aureus was also observed to Clindamycin (81.25\%), Amikacin (78.12\%), Cotrimoxazole (75\%), Gentamycin $(68.75 \%)$ and Azithromycin (68.75\%).

Of the 32 isolates of Staphylococcus aureus $15(46.87 \%)$ were identified as methicillin resistant. This high rate of isolation of MRSA was in concordance with few other studies. $^{[22,23]}$

All 3 isolates of CONS were isolated from orthopedic implants. However, the most frequent isolation of Escherichia coli (a normal gut flora) and Staphylococcus aureus (a normal skin commensal) from surgical site wound samples necessitates the need for strict aseptic surgical procedures and hospital infection control policies.

In conclusion, the rapid rise in antibiotic resistance in microorganisms due to selection pressure and production of extended spectrum $\beta$ lactamases, necessitates a proper antibiotic stewardship programme and development of Institutional antibiotic policies in hospitals. Restricted antimicrobial formalaries should be used only in selective situations under the strict guidance of Hospital Infection Control Committee.

Training of nursing staff, technicians in postoperative wards regarding maintenance of strict aseptic environment and interaction between clinicians and microbiologists needs to be emphasised. Protocols should be developed for preoperative workup and postoperative care to control risk factors causing surgical site infections.

\section{Conflict of interest}

The authors do not have any conflict of interest.

\section{References}

1. Richard, J Howard surgical infections. Principles of surgery, Schwartz $7^{\text {th }}$ Edition Pg 123-154.

2. Haley, $\mathrm{R} \mathrm{W}$.extra changes and the prolongation of stay attributed 51-58.

3. Cuchitra Joycee B, Lakshmidevi N. Surgical site Infections: Assessing Risk Factors, Outcomes and Antimicrobial Sensitivity Patterns. African Journal Of Microbiology Research (April2009): Vol.3 (4):175-179.

4. Finn Gottrup, Andrew S Vleling, Dirk A. An Overview of surgical site infections: Etiology, Incidence And Risk Factors. Ewma Journal (2005); Vol.5 (2):11-15.

5. Mulugeta, K. Azene, Bayeh A. Beyene. Bacteriology and Antibiogram of Pathogens From Wound Infections At Disease Laboratory, North East Ethiopia." Post graduate medical journal of Names Tanzania Journal of Health Research. (Oct 2011); Vol.13 (14)1-9.

6. Altemeier, W A Burke J. F. et al. Manual on control of infection in surgical patients, second edn., Philadelphia. J.B. Lippincott 1984:29.

7. Reichardt Paul F., "Gawain and the image of the wound" PMLA (1984). 99(2): 154161.

8. DR Arora, B Arora, Textbook of Microbiology, $3^{\text {rd }}$ edition infective syndrome chapter 69 (2008) 695.

9. Garner, JS (1996) Centers for Disease Control and Prevention, Health care inspection Control practices advisory committee, Guidelines for isolation precautions in hospitals, Infection Control and Hospital Epidemiology; 1: 53-80.

10. Lilani, SP, Jangale N, Chowdhary A. B. Daver GB. Surgical site infection in clean and clean-contaminated cases. Indian Journal Medical Microbiol., 2005; 23:249-52].

11. Collee, J.G., Marr W. Culture of bacteria. In: Collee JG, Fraser AG, Marmion BP, Simmons A (eds). Mackie \& McCartney 
Practical Medical Microbiology. $14^{\text {th }}$ Ed. London: Churchill Livingstone, 113-129.

12. Collee, J.G., Miles R.S., Watt B. Tests for the identification of bacteria. In: Collee JG, Fraser AG, Marmion BP, Simmons A (eds). Mackie \& McCartney Practical Medical Microbiology. $14^{\text {th }}$ Ed. London: Churchill Livingstone, 131-149.

13. Clinical and Laboratory Standard Institute. Performance standards for antimicrobial susceptibility testing; $27^{\text {th }}$ edition, CLSI M100-S17. Vol. 37 no.1. Wayne, PA: Clinical and Laboratory Standards Institute; 2017.

14. Anvikar, A.R., et al., A one year prospective study of 3280 surgical wounds. Indian J Medical Microbiology 1999. 17(3): 129-132.

15. Mamta Meena, et al., Aerobic bacteriological profile of post operative wound infection in tertiary care hospital, Bhopal. Journal of Microbiology and related research Vol-4(2) January-June 2018; 10-16.

16. Patel, Sachin et al., Surgical Site Infections: Incidence and risk factors in a tertiary care hospital, Western India. National Journal of Community Medicine 3(2) April-June 2012; 193-6

17. Satyanarayana, V. et al., Study of Surgical Site Infections in Abdominal surgeries. Journal of clinical and diagnostic research; 2011, October, Vol-5(5):935-9.

18. Rugira, Trojan et al., Antibiotic Susceptibility Patterns of Bacterial Isolates from Pus Samples in a Tertiary Care Hospital of Punjab, India.
International Journal of Microbiology Volume 2016.

19. Singh, V., et al., Surgical Site Infections A Hospital Havoc: Retrospective Study of Surgical Site Infections in Tertiary Health Care Centre in North East India. International Journal of Innovative Research in Medical Sciences (IJIRMS); Vol 03 issue 01 January 2018.

20. Bubonja-Sonje, M., et al., "Mechanisms of carbapenem resistance in multidrugresistant clinical isolates of Pseudomonas aeruginosa from a Croatian hospital," Microbial Drug Resistance, vol.21, no.3 pp.261-269, 2015.

21. Labarca, J.A., et al., "Carbapenem resistance in Pseudomonas aeruginosa and Acinetobacter baumannii in the nosocomial setting in Latin America," Critical review of Microbiology, vol. 42, no. 2, pp. 276-292, 2016.

22. Muluye, D.Y. Wondimeneh, G. Ferede et al., "Bacterial isolates and their antibiotic susceptibility patterns among patients with pus and/or wound discharge at Gondar university hospital," BMC Research Notes, vol. 7, no. 1, article 619, 2014. ;

23. Ruiz, J., et al., "From MIC creep to MIC decline: Staphylococcus aureus antibiotic susceptibility evolution over the last 4 years," Clinical Microbiology and Infection, vol. 22, no. 8, pp. 741-742, 2016.

\section{How to cite this article:}

Afreen Rashid, Talat Masoodi, Amrish Kohli, Sumaira Qayoom, Syed Arshi and Syed Khursheed. 2019. Aerobic Bacteriological Profile and Antibiogram of Surgical Site Infections in a Tertiary Care Hospital in Kashmir. Int.J.Curr.Microbiol.App.Sci. 8(04): 1881-1888. doi: https://doi.org/10.20546/ijcmas.2019.804.220 